\title{
O Direito Achado na Rua: Concepção e Prática, de José Geraldo de Sousa Júnior
}

[SOUSA JÚNIOR, José Geraldo (org). O Direito Achado na Rua:

Concepção e Prática. Rio de Janeiro: Lumen Juris, 2015, 260p.]

O livro "O Direito Achado na Rua: Concepção e Prática", organizado por José Geraldo de Sousa Júnior, coloca-nos diante de um processo coletivo de sistematização e análise dos legados (e dos desafios) epistemológico, teórico, metodológico e prático de um dos mais importantes referenciais da teoria crítica do Direito no Brasil, concebido pelo fundador da Nova Escola Jurídica Brasileira (NAIR), Roberto Lyra Filho - ainda nos idos de 1986, ano também de sua prematura morte, e que completa, em 2016, 30 anos de morte e 90 anos de nascimento - e depois teorizado e institucionalizado por José Geraldo de Sousa Júnior, fundador do grupo de O Direito Achado na Rua, com sede na Faculdade de Direito da Universidade de Brasília (UnB).

Para ler este livro é preciso ter um olhar atento para as duas questões que mobilizam seu subtítulo: "concepção" e "prática". A revisitação dos referenciais que fundamentam a "filosofia jurídica" de O Direito Achado na Rua é uma constante ao longo de todos os textos,

1 Professor de Direitos Humanos da Faculdade de Etnodiversidade da UFPA, Campus de Altamira. Doutorando pelo Programa de Pós-Graduação em Direito da Universidade de Brasília (UnB). Mestre pelo Programa de Pós-Graduação em Direito da Universidade Federal do Pará (UFPA). Bacharel em Direito pela UFPA. Secretário de articulação do Instituto de Pesquisa, Direitos e Movimentos Sociais (IPDMS). Advogado. E-mail: assisdco@gmail.com 
revisitação que, feita de maneira coletiva e, fundamentalmente, por estudantes de mestrado, doutorado, representantes de movimentos sociais e pelo organizador da obra, resulta num trabalho dinâmico de reapropriação e atualização das leituras e formas de embasamento. Por outro lado, é também uma obra que evidencia a "prática" desde seu título. E, com isso, querem as autoras e os autores abordar um conjunto de ações feitas ao longo dos 28 anos de existência do grupo no campo do ensino, da pesquisa e da extensão na UnB, e em muitos outros espaços, acadêmicos ou não, onde as sementes de O Direito Achado na Rua germinaram experiências de produção crítica dos direitos e de valorização dos conhecimentos dos sujeitos coletivos.

Na Introdução, Sousa Júnior pontua que a concepção editorial da obra foi estruturada em conjunto com os estudantes de duas disciplinas - "O Direito Achado na Rua (no mestrado e doutorado da Faculdade de Direito da UnB) e "Tópicos Especiais em Direitos Humanos e Cidadania (do mestrado do Programa de Pós-Graduação em Direitos Humanos e Cidadania da UnB), com textos elaborados ao longo do primeiro semestre de 2014, "tendo como eixo recuperar, no percurso de Roberto Lyra Filho, a concepção e a prática de O Direito Achado na Rua e a sua fortuna crítica. Assim também a sua história e desenvolvimento, as exigências críticas para a pesquisa, a extensão e o ensino em direito e em direitos humanos, que decorrem de O Direito Achado na Rua e que desafios, tarefas e perspectivas atuais se põem tendo em vista a continuidade do projeto e das ações e reflexões deduzidas dos coletivos que em torno dele se formam" (p. 6).

Cada aspecto desses objetivos se converterá num capítulo do livro, num total de quatro, escritos de maneira coletiva pelas e pelos estudantes. Mas, antes de adentrar nos capítulos, a Introdução convida o olhar mais aguçado do leitor, pois nela está contida não apenas uma análise histórica da concepção e da prática de O Direito Achado na Rua, mas um diálogo respeitoso e acolhedor do autor com os textos escritos pelos estudantes, procurando apontar aspectos relevantes de suas argumentações e o modo como se fundamentam em $\mathrm{O}$ Direito Achado na Rua. 
No primeiro capítulo, "O Direito Achado na Rua: concepção e prática. No percurso de Roberto Lyra Filho", Antonio Escrivão Filho, Fredson Oliveira Carneiro, Karoline Ferreira Martins, Priscila Paz Godoy, Raquel Negreiros Silva Lima, Roberta Amanajás Monteiro, Rodrigo Melo Mesquita e Valquíria Theodoro, analisam as bases teórico-conceituais de Roberto Lyra Filho que fundamentam O Direito Achado na Rua. Para tanto, abordam a centralidade da teoria lyriana em que "o Direito só existe e se perpetua na medida em que é movimento histórico de transformação dialética" (p. 64).

Nesse sentido, Escrivão Filho et al indicam que o NAIR assenta-se na ideia do humanismo dialético - pensado assim para dar evidência à historicidade dialética da liberdade - enquanto "conceito operativo, na medida em que oferecia resposta à antinomia aparentemente insolúvel entre a Justiça e a Lei" (p. 72). Com isso, estrutura-se em cinco metas: "(i) resgatar a dignidade política do Direito, (ii) apoiar aos movimentos progressistas libertadores, (iii) reagir e opor-se a relativistas e reacionários, bem como (iv) defender um socialismo democrático" (p. 72).

Trata-se da Dialética Social do Direito, a qual buscará "devolver o fenômeno jurídico ao seio social do qual surge" (p. 77), evidenciando as forças sociais em conflito e com pretensões normativas distintas. Portanto, é nas relações sociais que se deve analisar o fenômeno jurídico, influenciado pelo modo de produção capitalista, num processo histórico de constante (re)formulação dos conflitos e do Direito, resultando, na teoria lyriana, na compreensão do Direito como legítima organização social da liberdade, o que desloca o olhar do jurista da norma e do Estado para "a sociedade concreta, dinâmica e plural, pois é nela mesma que o Direito se constrói: nas ruas” (p. 82).

No segundo capítulo, denominado "A Fortuna Crítica de O Direito Achado na Rua: História e Desenvolvimento", escrito por Carlos Inácio Prates, Eneida Vinhaes BelloDultra, Gianmarco Loures Ferreira e Rafael de Acypreste, discuti-se o percurso e o desenvolvimento de O Direito Achado na Rua, em suas perspectivas epistemológicas, teóricas e práticas.

A ideia de "fortuna crítica" remete ao reconhecimento dos legados, teóricos e práticos, que forjaram a materialização de O Direito Achado 
na Rua. Tal legado é contextualizado pelas autoras e pelos autores no marco da década de 1980 que ensejou a produção de expressões teóricas críticas ao Direito, a exemplo do Direito Alternativo e do Direito Insurgente, duas concepções que são esmiuçadas em suas fundamentações, para revelar que ambas, assim como O Direito Achado na Rua, são formulações localizadas na Sociologia Jurídica e que de diferentes modos trabalham com a ideia do pluralismo jurídico, ainda que não haja, no texto, uma análise comparativa das teorias para identificar os pontos de aproximação e de dissonância.

Para Prates et al, o pluralismo jurídico é compreendido como base epistemológica de O Direito Achado na Rua. Por isso, para além da ideia comum de negação do poder centralizador do Estado de regulação dos direitos, está o reconhecimento das "mais diversas e crescentes manifestações normativas não estatais (informais), trazidas pelos novos sujeitos coletivos de direito (organizações e movimentos sociais)" (p. 106). Por isso, adotando a dimensão pluralista do Direito, as autoras e os autores, num segundo momento, indicam que $O$ Direito Achado na Rua se insere no âmbito da ciência jurídica antidogmática. Daí que sua sustentação teórica não apenas refuta a verdade posta de forma dogmática, mas propõe que se desloque o olhar para a pluralidade de fontes de produção do Direito, visando à superação da relação entre teoria e prática, a apreensão do caráter político da produção normativa e "reconhecendo o espaço político no qual se desenvolvem as práticas sociais também como enunciadoras de direitos" (p. 108).

Duas questões são destacadas dessa análise por Prates et al para evidenciar a consistência da práxis de O Direito Achado na Rua. A primeira, relacionada à problematização dos sujeitos coletivos, não apenas para reforçar o modo como suas vivências e experiências tornam-se focos de enunciação de direitos, o que coloca a tarefa árdua (aos sujeitos coletivos e ao Direito Achado na Rua) de disputar a invisibilidade forçada desse processo, mas também de visualizar o tenciosamento da esfera pública como palco de efervescência da democracia e, nela, da cidadania ativa.

O segundo aspecto é propriamente uma pergunta: a Constituição de 1988 esgotou a demanda por pluralismo jurídico? As autoras e os 
autores, sem deixar de reconhecer os avanços jurídicos trazidos pela Constituição Federal de 1988, indicam ser "necessário ter em vista os limites de efetividade de uma norma posta, ainda que seja no texto da lei maior" (p. 141), pois sua positivação não garante o avanço de concretização fática do conteúdo e a apreciação dos direitos unicamente pelo viés normativo do texto constitucional desloca seu caráter político das ruas para o Poder Judiciário. Logo, faz-se necessário retomar o entendimento do Direito para além do simples cumprimento das leis, não apenas para conectá-lo ao seu espaço público por excelência, as ruas, mas para continuar a captar - e, até, constitucionalizar - direitos a partir das demandas sociais proveniente das ruas.

O terceiro capítulo, denominado "O Direito Achado na Rua: Exigências Críticas para a Pesquisa, a Extensão e o Ensino em Direito e em Direitos Humanos" é uma construção coletiva de mulheres - Érika Lula de Medeiros, Helga Maria Martins de Paula, Ludmila Cerqueira Correia, Mariana Pereira Conceição, Priscila Bessa Rodrigues, Raquel Cerqueira Santos e Talita Tatiana Dias Rampin - e aprofunda a caracterização do ensino, da pesquisa e da extensão para O Direito Achado na Rua.

No âmbito do ensino jurídico, e partir das ideias de Roberto Lyra Filho, as autoras colocam a necessidade de reposicionamento crítico da atividade docente para assumir uma dimensão do ensino alinhada à compreensão do Direito como libertação, também reivindicando ao ensino sua condição de prática emancipatória que reconhece a e o estudante "como sujeito que se apropria do ser/fazer universitário e protagoniza o processo de construção dialógica do conhecimento" (p. 157).

Na pesquisa jurídica, as autoras, tendo por base os escritos de José Geraldo de Sousa Júnior e Roberto Lyra Filho, circunscrevem que tal atividade tem, em O Direito Achado na Rua, o compromisso de refletir "a realidade e as práticas sociais com e a partir de sujeitos coletivos de direitos" (p. 160), utilizando-se da teoria dialética do Direito para estimular um pensar politizado sobre e no Direito e um reposicionamento sobre os objetivos de pesquisa e a forma de analisá-los, de modo a estabelecer a opções metodológica pela pesquisa-ação por conceber 
a pesquisa como forma de intervenção na realidade, desde uma perspectiva emancipatória.

Quanto à extensão, afincada nos pressupostos de Paulo Freire, as autoras indicam a apreensão por O Direito Achado na Rua como extensão (jurídica) popular que resgate a responsabilidade social da universidade com seu contexto e a capacidade de construção de um trabalho cooperativo e solidário que proporcione a compreensão crítica do Direito às e aos sujeitos envolvidos, especialmente nas e nos estudantes, solidificando uma concepção dialética entre teoria e prática, ou seja, "o conhecimento acadêmico sendo praticado correlacionado à comunidade, na busca de romper as barreiras de uma academia introspectiva" (p. 171-172).

No último capítulo do livro, intitulado "O Direito Achado na Rua: Desafios, Tarefas e Perspectivas Atuais", de autoria coletiva de Diego Mendonça, Euzamara de Carvalho, Mayane Burti, Paulo César Machado Feitoza, Pedro Brandão, Renata Cristina do Nascimento Antão e Tedney Moreira da Silva, há um constante questionamento das projeções de futuro de O Direito Achado na Rua, feito a partir de uma dimensão prática e coletiva de avaliação e de planejamento das próximas tarefas, subdividido em três áreas: teórico-epistemológico; pedagógico; e, práxis-participação popular.

No âmbito epistemológico, o pluralismo jurídico é colocado como uma contínua tarefa de atualização em termos de conceituação, métodos e resultados, mas também de identificação dos atores sociais emergentes e da ressignificação das práticas emancipatórias dos sujeitos de direitos. Nisso, o campo do novo constitucionalismo latino-americano e sua replicação nos formatos do pluralismo jurídico podem ensejar a conformação de um "Constitucionalismo Achado na Rua", assim como colocar em evidencia a necessidade de repensar o constitucionalismo brasileiro a partir das experiências de outros países latino-americanos.

O segundo desafio epistemológico é do diálogo com a práxis da descolonização do saber, tarefa de trabalhar com o conceito de sujeitos de direito acompanhado do conceito de sujeitos de conhecimento 
"que envolve o processo de ensino e aprendizagem recíprocos entre os diferentes saberes" (p. 226). Para as autoras e os autores, o tema envolve o desafio da abertura da universidade para outros saberes, sobretudo a partir da ferramenta das ações afirmativas, sem, no entanto, chegarem a refletir sobre as formas de aproximação de O Direito Achado na Rua com as teorias pós-coloniais e descoloniais do poder, dos direitos e do Estado.

Na segunda área, a pedagógica, estão os desafios para o ensino, a pesquisa e a extensão, em que se (re)coloca a necessidade de reinvenção do ensino, da pesquisa e da extensão por O Direito Achado na Rua, numa perspectiva crítica de "disputar um modelo de academia que valorize outras narrativas e formas de saberes" (p. 229) a partir dos sujeitos coletivos de direito e, por isso mesmo, de disputar a hegemonia da concepção e da gestão do e no Direito.

Por fim, na práxis e participação popular, Mendonça et al problematizam as tarefas de O Direito Achado na Rua a partir de uma vasta miríade de questões (ou desafios) apontados pelas e pelos interlocutores, das quais cabe destacar a continuidade da disputa pelo modelo e pelo discurso da democracia, assentando, cada vez mais, numa produção teórica e prática que valorize o caráter seu participativo; e, a necessidade de estar atento às transformações sofridas pelos sujeitos coletivos de direito, não apenas em relação às suas pautas, de modo a pensar a identificação e a integração entre elas, mas também em termos organizativos, com atenção ao uso das novas tecnologias de comunicação e a maneira como estão "repolitizando a luta pela garantia e efetividade de direitos e o pleito dos sujeitos que militam por direitos socais (p. 246). 